\title{
Groundwater Flow Modeling in Coastal Aquifers: The Influence of Submarine Groundwater Discharge on the Position of the Saltwater - Freshwater Interface
}

\author{
Haile Arefayne Shishaye* \\ Haramaya University, Dire Dawa, Ethiopia
}

\begin{abstract}
An investigation of the impact of submarine groundwater discharge on the position of saltwater-freshwater interface is presented in this manuscript. Two conceptualizations were considered and analyzed using both analytic and numerical techniques, for comparison purposes. The first conceptualization assumes that the tip of the saltwaterfreshwater interface occurs at the shoreline, and the second conceptualization allows for the tip to extend off-shore. Analytic solutions exist for both conceptualizations. Results from both analytic and numeric analysis for the two conceptualizations are presented. Results from the first conceptualization were found to overestimate the inland distance to the interface toe, compared to the second conceptualization, for it ignores the influence of submarine groundwater discharge on the interface location. Moreover, results from the analytic solutions as a whole were found to overestimate the interface location compared to the numerical modeling results, for analytic solutions are based on the sharp interface approximations. Therefore, an empirically derived dispersion factor should be used to correct the analytic solution results so as to compare them with the numerically simulated values. Furthermore, offshore model extents should be incorporated when modeling coastal aquifer systems to include the influence of submarine groundwater discharge on the saltwater-freshwater interface position.
\end{abstract}

Keywords: Groundwater flow modelling; Seawater intrusion; Submarine groundwater discharge; Seawat; Analytic solution; Numerical modelling

\section{Introduction}

Seawater intrusion is the migration of saline water into freshwater in coastal aquifers. Saline water is denser than freshwater, for it has higher mineral contents. Consequently, it forms a wedge beneath freshwater in coastal aquifers (Figure 1). Seawater intrusion can occur naturally owing to the connectivity between seawater and groundwater, and due to certain human activities. Therefore, modeling the coastal groundwater flow system enables the evaluation of the potential for seawater intrusion into aquifer systems as a result of different factors. However, modeling saltwater intrusion is considered difficult. Factors such as heterogeneity of the aquifer hydraulic properties, the complicated aquifer geometries and the temporal and spatial variability in groundwater density make it difficult to model seawater intrusion [1].

The accuracies of model outputs are strongly based on the assumptions made on the model input parameters. Seawater intrusion model results for the saltwater-freshwater interface position, for example, are strongly affected by different factors such as boundary conditions, initial (head and concentration) conditions and aquifer hydraulic properties. Furthermore, nowadays, Submarine Groundwater Discharge (SGD) is also becoming an important issue to be considered in modeling coastal groundwater systems. Owing to seawater intrusion, the land driven fresh groundwater can discharge to the seafloor through the leaky confining unit and the process is called SGD [2-4]. This kind of discharge decreases with the increase in distance offshore and is zero where the tip of the interface touches the leaky confining unit [5].

Several authors have studied seawater intrusion and the position of the saltwater-freshwater interface owing to different factors in coastal aquifers. Strack [6] developed an analytic solution for the regional interface problems in coastal aquifers based on the single-valued potentials, the Dupuit assumption and the Ghyben-Herzberg formula for the steady state flow conditions. The Strack [6] analytic solution has been widely used by different researchers to explore seawater intrusion in coastal aquifers [1,5,7-10]. Different seawater intrusion assessment methods have also been developed based on the Strack [6] analytic solution [11,12].

Other authors like Huyakorn et al. [13], who presented a numerical model based on the sharp interface approach and taking into account the flow dynamics of saltwater and freshwater, Motz [14], who proposed an analytic solution for calculating the critical pumping flow rate in an artesian aquifer, and Bower et al. [15], who modified the critical interface rise based on the analytic solution which allows the critical pumping rate to be increased are also some of the well-known studies conducted on seawater intrusion in costal aquifers.

However, none of the above papers consider the influence of SGD on the seawater-freshwater interface position. There is no possibility to simulate the offshore groundwater discharges using the above analytic solutions, unless modifications are made to include the offshore outflow zone of the land driven fresh groundwater through the seafloor by taking model extent offshore into consideration. Recently, Bakker [16] has modified the Strack solution so as to include the offshore freshwater outflow zone. It is a solution for a steady interface flow in confined coastal aquifers discharging to a semi-confined section below the ocean. Bakker has shown that the tip of the saltwater-freshwater interface can

*Corresponding author: Haile Arefayne Shishaye, Haramaya University, Dire Dawa, Ethiopia, Tel: +251942124463; E-mail: haile.4.hiwot@gmail.com

Received January 20, 2016; Accepted February 10, 2016; Published February 17,2016

Citation: Shishaye HA (2016) Groundwater Flow Modeling in Coastal Aquifers: The Influence of Submarine Groundwater Discharge on the Position of the Saltwater-Freshwater Interface. J Coast Zone Manag 19: 419. doi:10.4172/24733350.1000419

Copyright: (C) 2016 Shishaye HA. This is an open-access article distributed under the terms of the Creative Commons Attribution License, which permits unrestricted use, distribution, and reproduction in any medium, provided the original author and source are credited. 
perhaps touch the leaky confining unit at some distance offshore, and this depends on the head of the land driven fresh groundwater and the leakage factor of the seafloor. Hence, the decision on how long a model should be extended offshore for accurate simulations of the interface position is also an important consideration when modeling coastal groundwater flow systems [17]. In general, to identify the knowledge gap in our current advances in seawater intrusion and the influence of submarine groundwater discharge on the position of the saltwaterfreshwater interface, a comparison among the previously developed and widely in use analytical and numerical models on the area is very crucial. Such a comparison can show the gaps within the developed models and can also give directions to fill the knowledge gaps in the area.

The objective of this manuscript is therefore to investigate the influence of SGD on the position of saltwater-freshwater interface. To do so, comparing the steady state interface location when two conceptualizations are used in both analytic and numerical modeling techniques could be very important. The first conceptualization is based on the Strack [6] analytic solution, assuming that the tip of the interface lies at the shoreline; while, the second conceptualization is based on the Bakker [16], taking the distance offshore into consideration.

\section{Common parameters and values used}

A homogeneous and isotropic coastal aquifer with confined and semi-confined sections and of constant thickness $H[\mathrm{~L}]$ was considered in this generic research. A Steady state condition is assumed and pumping is not considered. The inflow to the aquifer at the inland boundary is $Q_{0}\left[\mathrm{~L} \mathrm{~T}^{-1}\right]$ (Figure 1). The confining unit has a thickness $H_{V}$ [L] and resistivity factor $c[\mathrm{~T}]$. The aquifer bottom has a depth $H_{b}[\mathrm{~L}]$ below sea level, while the bottom of the confining unit is $H_{l}[\mathrm{~L}]$ below sea level. A dimensionless density factor $\delta$ is given by $\left(\rho_{s}-\rho_{f}\right) / \rho_{\rho}$ where $\rho_{s}\left[\mathrm{M} / \mathrm{L}^{3}\right]$ is the saltwater density and $\rho_{f}\left[\mathrm{M} / \mathrm{L}^{3}\right]$ is freshwater density. The following parameter values were taken from the study conducted in Madras aquifer (in the city of Madras, now called Chennai, India) by Sherif et al. [18]. These values were then used in both conceptualisations of the analytic and numerical modellings.

\section{Methodology}

\section{Analytical modelling}

Strack [6] analytic solution: Strack has developed an equation for the continuous discharge potential $(\Phi)$ within the multiple zones of the aquifer based on the Girinski equations. He added a constant to the Girinski equation for the discharge potentials. i.e,

$$
\Phi=\frac{1}{2} K \frac{\rho_{f}}{\rho_{s}-\rho_{f}}\left[h_{f}-H_{s} \frac{\rho_{s}}{\rho_{f}}+H \frac{\rho_{s}-\rho_{f}}{\rho_{f}}\right]^{2}+C_{c i}
$$

where, $h_{f}=H_{s} \frac{\rho_{s}}{\rho_{f}}$ and $C_{c i}$ is a constant

Substituting $H_{s} \frac{\rho_{s}}{\rho_{f}}$ in place of $h_{f}$ will give the following:

$\Phi=\frac{1}{2} K \frac{\rho_{s}-\rho_{f}}{\rho_{f}} * H^{2}$

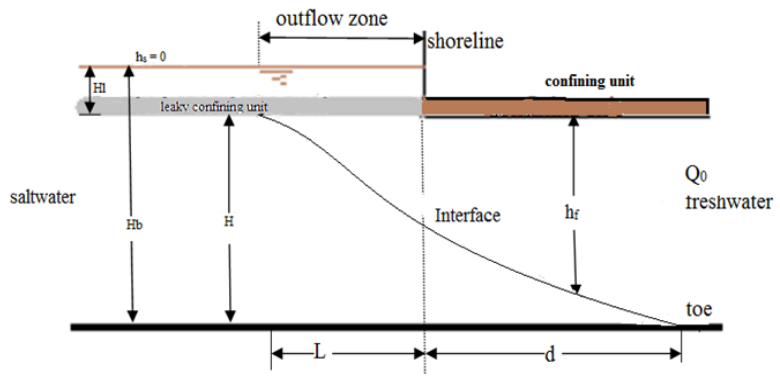

Figure 1: Seawater intrusion conceptual diagram.

The discharge potential $\Phi$ is given by $Q_{0} X_{i}$, where $Q_{0}$ is the inflow to the confined aquifer and $X_{i}$ is the onshore distance. If the toe of the interface is assumed to be located at $X=d$, then,

$$
d=\frac{\Phi_{d}}{Q_{0}}
$$

where, $\Phi_{d}$ is the discharge potential at a distance of $d$ from the coast.

Bakker [16] analytic solution: The vertically integrated freshwater discharge of the confined aquifer in the horizontal-direction is given in the Bakker (2006) analytic solution by:

$$
Q_{0}=K h_{f} \frac{d h}{d x}
$$

where, $h_{f}$ is the thickness of the freshwater zone. From this, the following procedures were followed to derive simplified equations, based on the Bakker [16], for the discharge potential at the toe (where the thickness of the freshwater zone is equal to the thickness of the aquifer, i.e., $h_{f}=H$ ), lengths onshore and offshore and the interface heads.

As described above, the thickness of the freshwater zone is equal to the thickness of the aquifer i.e., $\boldsymbol{h}_{f}=\boldsymbol{H}$ at the toe of the interface. Substituting $h_{f}$ by $H$, both sides of equation (3) were integrated with respect to $x$ and $h$, respectively and yielded the following equation.

$$
Q_{0} X=\frac{1}{2} \delta K H^{2}
$$

The discharge potential at any distance $X=i$ is given by the product of the vertically integrated discharge in the confined aquifer and the distance " $i$ " from the shoreline. The value of $X$ is 0 at the shoreline. Therefore, if it is assumed that the toe of the interface is at a distance $X=d$ from the shoreline, then the discharge potential at the toe will be given by $\Phi_{d}=Q_{0} d$. Thus, because of $Q d-K H$

$$
\Phi_{d}=\frac{1}{2} \delta K H^{2}
$$

In this case, if it is assumed that the tip of the interface lays at the coastline, the distance of the toe from the shoreline will be given by:

$$
d=\frac{\Phi_{d}}{Q_{0}}
$$

However, Bakker [16] has taken the distance offshore into consideration. Thus, the place where the discharge potential values become zero will not necessarily be at the coordinate where $X=0$. Therefore, 
the point where the discharge potential becomes zero lies where the tip of the interface touches the confining unit. So, the procedure to develop an equation for the discharge potential at the shoreline based on the Bakker (2006) analytic solution is similar to that of followed above, but with different head value. The interface head at the shoreline lies at a depth $Z_{0}$ below the sea level or $\left(H l-Z_{0}\right)$ below the bottom of the confining unit, where $\mathrm{Hl}$ is the depth of the confining unit below the sea level. Therefore, substituting $\left(H l-Z_{0}\right)^{2}$ in place of $H^{2}$ in equation (4) above will give the following equation for the discharge potential at the shoreline.

$$
\Phi_{0}=\frac{1}{2} \delta K\left(H l-Z_{0}\right)^{2}
$$

The discharge potential $\left(\Phi_{0}\right)$ is zero and $Z_{0}=H l$ at $X=0$ when the tip of the interface lays at the shoreline. From here, the equation for the distance of the interface toe from the shoreline might be different from equation (5), if the tip of the interface lays at some distance offshore. i.e,

$$
d=\frac{\left(\Phi_{d}-\Phi_{0}\right)}{Q_{0}}
$$

The model extent offshore $(L)$ is given in the Bakker (2006) analytic solution as:

$$
\frac{L}{\lambda}=(18 \mu)^{1 / 3}
$$

Where, $\mu=\frac{g_{c} \lambda_{d}}{\delta}$ and $\lambda=\sqrt{K H c}$. The equations for $g_{c}$ and $\lambda_{d}$ are also given as $\frac{Q_{0}}{K H}$ and $\frac{\lambda}{H}$, respectively.

Therefore, equation (8) has been re-written as follows to develop an expression for the distance offshore $(L)$ in terms of the parameters given in (Table 1). So,

$$
L=\left(18 \frac{Q_{0} K c^{2}}{\delta}\right)^{1 / 3}
$$

Bakker has also developed an equation relating the distance offshore $(L)$ and the dimensionless head $(\phi)$, i.e., $u=-\sqrt{6 \varphi}+\frac{L}{\lambda}$, where $u$ is a
coordinate, $\varphi=\frac{h_{f}}{H}$ and $\leq \leq-$

According to Bakker (2006), $\phi=1$ and $u=0$ when the toe lies at the intersection point of the confined and semi-confined sections. Substituting these values will then give us:

$$
\begin{aligned}
& L=\sqrt{6} \lambda \\
& L^{2}=6 K H c
\end{aligned}
$$

Therefore, the interface head at the toe is calculated as follows:

$$
H=\left(\frac{18 Q_{0} K c^{2}}{\delta}\right)^{2 / 3} / 6 K c
$$

The depth of the interface $Z_{0}$ is based on the freshwater head at the shore line. In this case, $H$ represents the depth of the interface below the bottom of the confining unit (thickness of the freshwater head). This can also be written as:

\begin{tabular}{|l|l|l|l|}
\hline $\begin{array}{l}\text { Parameter } \\
\text { symbol }\end{array}$ & Parameter description & Values & Unit \\
\hline$Q_{o}$ & Inflow rate to the confined aquifer & 1.0 & $\begin{array}{l}\mathrm{m}^{3} / \\
\text { day }\end{array}$ \\
\hline$K$ & Hydraulic conductivity of the confined aquifer & 260.0 & $\mathrm{~m} /$ day \\
\hline$C$ & Vertical resistance of the leaky layer & 12.5 & day \\
\hline$H_{v}$ & Thickness of the confining unit & 5 & $\mathrm{~m}$ \\
\hline$H I$ & $\begin{array}{l}\text { Depth of the leaky confining unit below sea } \\
\text { level }\end{array}$ & -10 & $\mathrm{~m}$ \\
\hline$H$ & Thickness of the confined aquifer & 20 & $\mathrm{~m}$ \\
\hline$h_{s}$ & Sea level & 0.0 & $\mathrm{~m}$ \\
\hline$H_{b}$ & $\begin{array}{l}\text { Depth of the confined aquifer bottom below } \\
\text { sea level }\end{array}$ & -30 & $\mathrm{~m}$ \\
\hline$\delta$ & Dimensionless density factor & 0.025 & - \\
\hline$\rho_{s}$ & Density of saltwater & 1025 & $\mathrm{~kg} / \mathrm{m}^{3}$ \\
\hline$\rho_{f}$ & Density of freshwater & 1000 & $\mathrm{~kg} / \mathrm{m}^{3}$ \\
\hline
\end{tabular}

Table 1: SWI simulation parameters, values and units.

$$
\begin{gathered}
h_{f}=\left(\frac{18 Q_{0} K c^{2}}{\delta}\right)^{2 / 3} / 6 K c \\
Z_{0}=H l-\left(\frac{18 Q_{0} K c^{2}}{\delta}\right)^{2 / 3} / 6 K c
\end{gathered}
$$

Thus, the depth of the interface below sea level $\left(Z_{0}\right)$ is calculated as follows:

Hence, the plotting plane can be divided into two zones, the offshore and onshore zones. The saltwater-freshwater interface heads along the two zones can be plotted against the offshore and onshore distances. For example, let " $X 1$ "represents the list of equally spaced 100 numbers from 0 to $-\mathrm{d}$ and " $X 2$ "represents the list of equally spaced 100 numbers from 0 to $L$. It is also possible to increase or decrease the list of numbers within the range to increase the plotting accuracy. Therefore, in this case, plotting can be completed within two steps. Step 1 is to plot $X 1$ against $(Z 1+30)$ and step 2 is to plot $X 2$ against $(Z 2+30)$, where," 30 " is the depth of the bottom of the aquifer below sea level and $Z 1$ and $Z 2$ are calculated as follows.

$$
\Phi_{d}=\frac{1}{2} \delta \mathrm{KH}^{2}
$$

From equation (4),

Form this,

$$
H^{2}=\frac{2 \Phi_{d}}{(\delta K)}
$$
the toe,

$$
h_{f}=\sqrt{\left(2 \Phi_{d}\right) /(\delta K)}
$$

Therefore, to derive an equation for the depth of the interface below the confining unit at any distance $X 1\left(h_{f x 1}\right)$, we need to calculate the total discharge potentials at any distance $X 1$. The value of $\Phi$ at a distance $X 1$ is given by $Q_{0} X 1$. Moreover, the total discharge potential at a distance of $X 1$ is $\left(Q_{0} X 1+\Phi_{0}\right)$. But because of that $X 1$ represents a list of 100 numbers from 0 to $-\mathrm{d}$, a negative sign should be included within the equation $Q_{0} X 1$.Therefore, substituting $\left(-Q_{0} X 1+\Phi_{0}\right)$ in place of $\Phi_{d}$ in equation (12), the depth of the interface $\left(h_{f x 1}\right)$ below the confining unit at any distance of $X 1$ is given by: 


$$
h_{f x 1}=\sqrt{\left(2\left(-Q_{0} X 1+\Phi_{0}\right) /(\delta K)\right.}
$$

The depth of the interface below sea level is, therefore, calculated as

$$
\begin{aligned}
& Z 1=H l-h_{f x 1} \\
& Z 1=H l-\sqrt{\left(2\left(-Q_{0} X 1+\Phi_{0}\right) /(\delta K)\right.}
\end{aligned}
$$

Further, the depth of the interface $\left(h_{f x 2}\right)$ at any distance offshore (X2) can also be calculated from eqn. (10). The point where the interface tip touches the leaky confining unit is when $\mathrm{Hl}$ is equal with $\mathrm{Z} 2$. This point is located at a distance where $X_{2}=L$ Therefore, because of that $X 2$ has 100 list of values, substituting $\mathrm{L}^{2}$ by $(\mathrm{X} 2-\mathrm{L})^{2}$ would help to calculate the depth of the interface below the confining unit at the 100 different $X 2$ values. Hence, the depth of the interface below the leaky confining unit $\left(h_{f x 2}\right)$ will be given as:

$$
h_{f x 2}=\frac{(X 2-L)^{2}}{6 \mathrm{Kc}}
$$

The depth of th nterface below sea level can then be calculated as:

$$
\begin{aligned}
& Z 2=H l-h_{f x 2} \\
& Z 2=H l-\frac{(X 2-L)^{2}}{6 \mathrm{Kc}}
\end{aligned}
$$

The depth from the sea level to the bottom of the aquifer is 30 (i.e., $H_{b}=-30$ ). Furthermore, the depth to the interface locations offshore is represented by $Z 2$ and to that of onshore is represented by $Z 1$. Therefore, $Z 1+30$ will result the hydraulic heads of the interface all along 0 to $\mathrm{d}$, and $Z 2+30$ will give the interface hydraulic heads all along 0 through $-L$. Remember that, the values for $Z 1$ and $Z 2$ are based on $X 1$ and $X 2$ (from equations 13 and 15), respectively. Therefore, $Z 1$ and $Z 2$ will represent a list of 100 numbers each. This implies that we have 100 points onshore and 100 points offshore to plot.

Numerical modeling: In addition to their use as planning tools for improving water supply and management, numerical models of groundwater systems are also useful for understanding groundwater flow processes. In terms of the use of modeling packages, groundwater flow systems can be divided into two, i.e., groundwater flow processes with constant density and the one with variable density. Simulating the groundwater systems in coastal aquifers which include saltwater and freshwater requires the use of a numerical modeling code that solves the variable-density flow equation (examples and perhaps widely used packages are SEAWAT and SUTRA).

SEAWAT is a generic MODFLOW/MT3DMS based computer program designed to simulate three-dimensional variable-density groundwater flow coupled with multi-species solute and heat transport. While, SUTRA is a general-purpose, density-dependent, fluid flow and mass-transport numerical model that applies a finite element and integrated finite-difference hybrid method, which is mainly used to model both the coastal surficial and confined aquifers [17]. In this case, the model used to investigate the impact of SGD on the position of saltwater-freshwater interface is the three dimensional SEAWAT model. SEAWAT has been used widely for groundwater studies including saltwater intrusion in coastal aquifers.

The type of aquifer considered in this paper is a confined coastal aquifer which is hydrogeologically connected with the seawater.
Similar to what was done in the analytic modeling section, numerical modeling was conducted based on the Strack [6] and Bakker [16] analytic solutions for the interface problems. The other consideration, in this simulation was that the confining unit offshore (the sea floor) is assumed to be a leaky confining unit. The common parameters used in both simulation cases are listed in Table 1.

Case 1- Modeling with no distance offshore: To obtain a steady state solution, the simulation run was divided into 10 stress periods, which in turn are divided into 10,000 time steps and 70,000 days of period length each, which corresponds to a total simulation period of 700,000 days. Modeling was conducted for case-1 by constructing a three dimensional SEAWAT model with an inland distance of 2600 meters, based on the Strack [6] analytic solution.

The SEAWAT model was used to simulate variable density groundwater flow in a three-dimensional cross section with 1 row, 130 columns, and 20 layers. The size of each model cell was set to $20 \mathrm{~m}$ horizontal by $1 \mathrm{~m}$ vertical. The top and bottom sides of the model were set to no-flow boundaries. The left side boundary is occupied by the seawater column with a constant head of $30 \mathrm{~m}$ and constant density of $35 \mathrm{~kg} / \mathrm{m}^{3}$; while, the right side boundary was set to a constant flux freshwater with an inflow rate of $1 \mathrm{~m}^{3}$ and density of $0 \mathrm{~kg} / \mathrm{m}^{3}$.

The model was initially run for 50,000days in a steady state simulation flow type. Then, the initial and prescribed head was taken from the steady state simulation as an input for the transient simulation flow type. Therefore, the initial and prescribed head used in this simulation was $30 \mathrm{~m}$. The initial concentrations were based on seawater concentrations, $35 \mathrm{~kg} / \mathrm{m}^{3}$ for columns 2 to 129 in all layers; while, column 1 (seawater column) was fixed to a concentration of $35 \mathrm{~kg} / \mathrm{m}^{3}$. The concentration for column 130 (freshwater column) was also set to 0 . A uniform and isotropic value for hydraulic conductivity was set to $260 \mathrm{~m} / \mathrm{d}$, the porosity was set to 0.35 , and the values for longitudinal and transverse dispersivities were set to $0.1 \mathrm{~m}$ each. The specific storage was also set to 0.0001 .

The SIP package of MODFLOW and the GCG package with the finite-difference option of MT3DMS/SEAWAT were used to solve systems of the flow and transport equations, respectively. The SIP solver was used with a head convergence criterion of $1 \times 10^{-4} \mathrm{~m}$ to solve the flow equation. Furthermore, the GCG solver was used with a courant number (number of cells or fraction of a cell that a parcel of water can advect during one time-step) of 0.75 to solve the solute-transport equation.

Case 2- Modeling with distance offshore: Modeling was conducted for case- 2 by constructing a three dimensional SEAWAT model with an inland and offshore distances of $2600 \mathrm{~m}$ and $400 \mathrm{~m}$, respectively, based on the Bakker [16] analytic solution.

The same dimensions, initial conditions, solver packages and aquifer properties to that of used in case- 1 were used in case-2. However, the boundary conditions were different between the two cases. The left, bottom, and from column 21 to 149 of the top layer were set to no flow boundaries. The right hand side (column 150) was set to constant flux with a constant inflow rate of $1 \mathrm{~m}^{3}$ and density of $0 \mathrm{~kg} / \mathrm{m}^{3}$. From column 1 to 20 of the top boundary, a general head boundary was applied with an external head of $10 \mathrm{~m}$, conductance of $2 \mathrm{~m}^{2} / \mathrm{d}$ and density of $35 \mathrm{~kg} /$ $\mathrm{m}^{3}$. This indicates that the model takes the SGD into consideration over the offshore distance specified above.

In this case, the impact of the seawater is through the general head boundary (the seafloor leakage). The vertical seawater column 
simulated in case- 1 is now neglected. However, when considering a long model extent offshore, up to the end of the continental shelf, the vertical constant head and density seawater column should be taken into account. The only reason for neglecting the vertical seawater column and simulating only the impact of the seawater through the leaky confining unit (General head boundary) in our case is because of that the offshore model extent considered is very short $(400 \mathrm{~m})$. Otherwise, both the vertical constant head and density seawater column and the leakage through the seafloor (in a semi confined scenario) should be taken into account during actual simulations.

\section{Result and Discussion}

\section{Analytic solution}

Case 1: The Strack [6] analytic solution is based on the use of the single potential which is defined throughout the multiple zones of an aquifer. Refer to Strack [6] to look at the assumptions based on which he developed his analytic solution.

However, this conceptualization only works in coastal aquifers with no SGD. Furthermore, the solution neglects the mixing factor, for it is based on the sharp interface approximation. Nevertheless, Strack's solution has been widely used in the area of coastal groundwater flow modeling.

Therefore, taking the above assumptions into consideration and

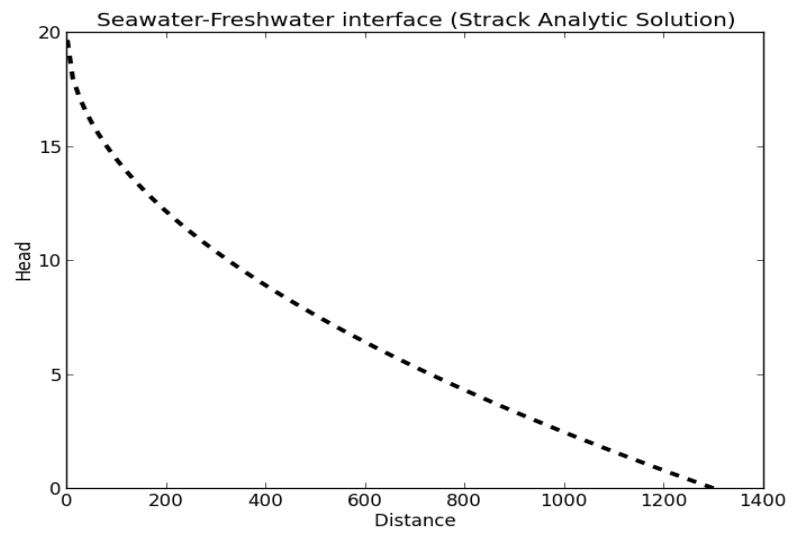

Figure 2: Strack (1976) seawater-freshwater interface.

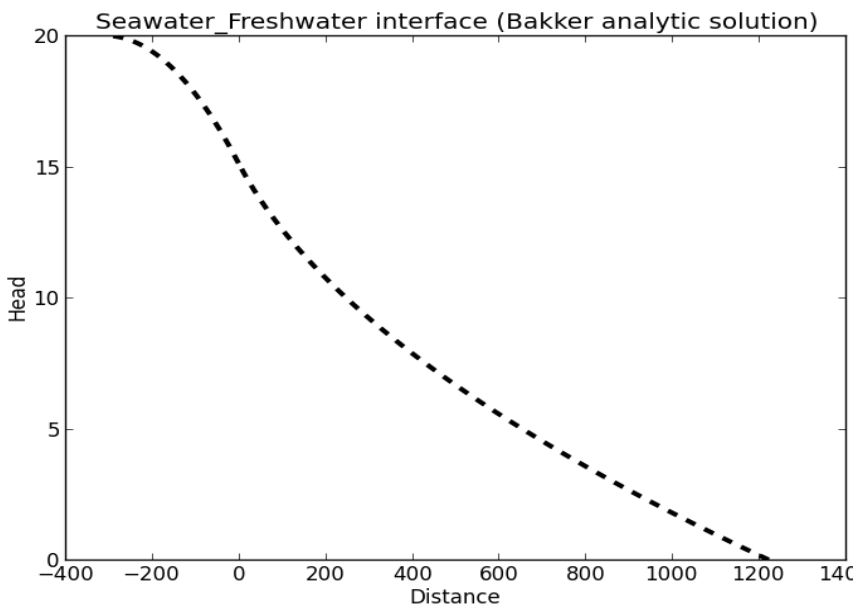

Figure 3: Bakker (2006) seawater-freshwater interface. using the common parameter values listed in table 1 , and equations 1 and 2, a python script of this conceptualization was developed, which has yielded the graph shown in Figure 2. In this case, the graph is showing that there is no offshore out flow zone included in the Strack's solution. The tip of the interface is located exactly at the shoreline; while, the toe was found at a distance of $1300 \mathrm{~m}$ inland.

Case 2: As indicated in the methodology part above, a python script was developed based on the Bakker [16] analytic solution. Common parameter values were also used with the Strack [6] analytic solution for comparison purposes. Similar to case-1, the interface heads vs. distance graph was plotted using the python package (Figure 3).

Bakker's analytic solution was developed for steady interface flow in aquifers consisting of confined and semi-confined sections. According to Bakker [16], the integrated discharge from all layers is constant in the confined section and is directed towards the semi-confined section, which is bounded on top by a leaky seafloor. The land driven fresh groundwater flows up through the leaky confining unit (seafloor). This discharge is, therefore, totally based on the freshwater-saltwater head differences, hydraulic properties of the aquifer materials and the leakage factor of the seafloor. Using the common values (Table 1), the toe of the interface in this case was found at an inland distance of $1222.97 \mathrm{~m}$; while, the tip was found at an offshore distance of $308.11 \mathrm{~m}$.

Plotting the two cases on one graph: The main difference between the two well known analytic solutions for the interface problems, Strack [6] and Bakker [16], is the distance offshore. Bakker [16] has taken the distance offshore into consideration to include the influence of SGD on the seawater-freshwater interface position; while, Strack [6] has not. This difference has created a difference on the position and shape of the interfaces developed using the two solutions.

As shown in Figure 4, the toe of the interface was found at a distance of $1222.97 \mathrm{~m}$ from the coastline using the Bakker [16] analytic solution, while it was found at a distance of $1300 \mathrm{~m}$ using the Strack [6] analytic solution. In this case, the SGD has created (1300 m-1222.97 m), 77.03 $\mathrm{m}$, gap in the location of the toe of the interface. In other words, the Strack [6] analytic solution has overestimated the location of the toe of the interface, for it doesn't consider the model extent offshore.

It is highly unlikely to find the saltwater column vertically fixed at the shoreline. Even though it varies from place to place, the continental shelves can perhaps be extended to hundreds and/or thousands of kilometers offshore. There are plenty of scientific evidences for the availability of SGD [2-4,19-23]. Therefore, it is important to consider the model extent offshore for accurate simulations of the position of saltwater-freshwater interface.

As shown in Figure 4, the length of the outflow zone was found to be $308.11 \mathrm{~m}$, using the Bakker [16] analytic solution; while, there is no outflow zone considered in the Strack [6] analytic solution. In fact, the gap between the simulated interface locations using the Bakker and Strack analytic solutions is getting wider from the toe to the tip. And this is because of the leakage factor included in the Bakker [16] analytic solution. The Bakker [16] analytic solution assumes two sections within the aquifer system, the confined and semi-confined conditions. Therefore, the appearance of the interface can possibly vary based on the values used for the leakage factor.

Thus, according to the simulation results, errors can be caused by ignoring the SGD during simulations. The extent of errors in confined aquifers may be greater than that of unconfined aquifers, for the flow 


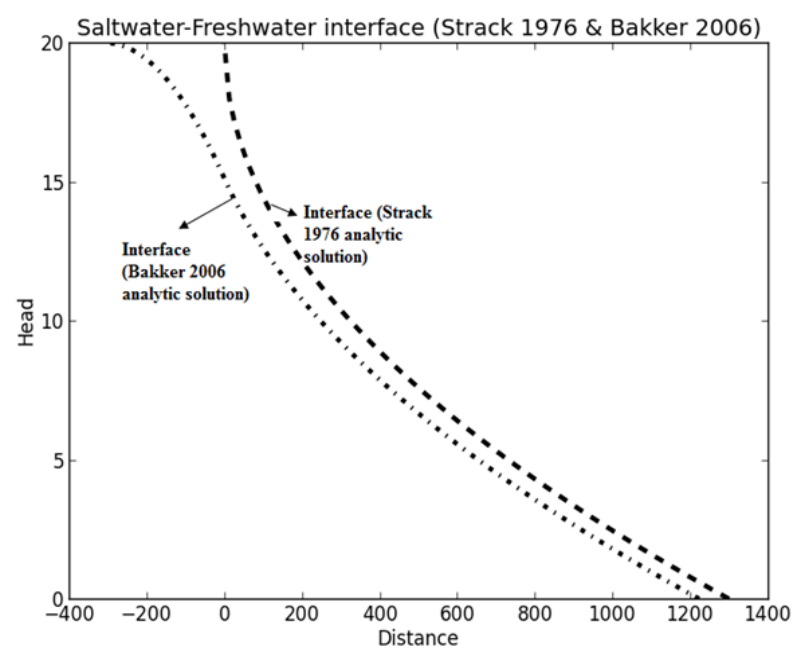

Figure 4: Plotting the two interface solutions in one.

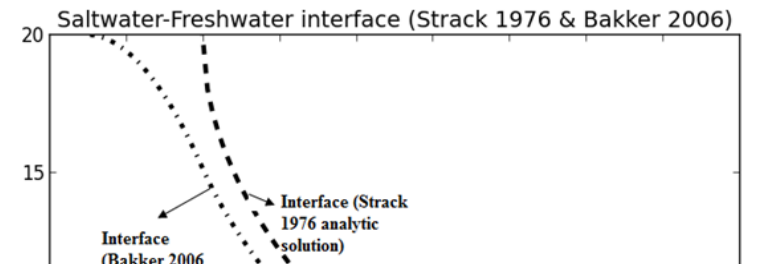

Figure 5: Seawater-freshwater interface (at $50 \%$ of the maximum concentration) of case-1.

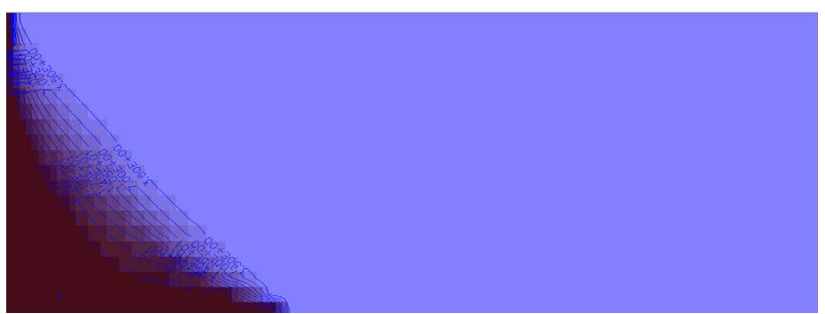

Figure 6: Contour map of case-1.

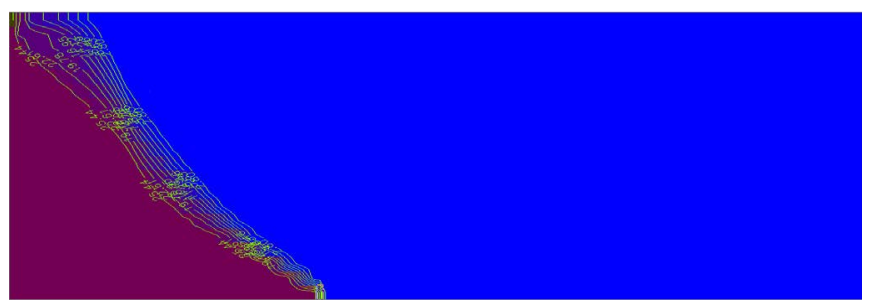

Figure 7: Contour map of case-2.

systems in equilibrium in confined aquifers may discharge hundreds of meters or even kilometers offshore depending on the hydraulic gradient and the geology of the formation [24]. However, regardless of whether conditions are confined or unconfined, error occurs in Strack's solution because it ignores the SGD.

\section{Numerical modeling}

Case 1: This conceptualization was based on the Strack [6] analytic solution for the interface problems. In this case, the concentration contour line at the $50 \%$ of the maximum concentration was chosen to represent the interface location. Accordingly, the tip of the seawaterfreshwater interface was found at the shoreline; while, the toe was found at an inland distance of $880 \mathrm{~m}$ (Figure 5). The distance to the toe location found in this case is shorter than the distance found in case- 1 of the analytic solution section. Both the analytic and numerical solutions of this case (case-1) were applied for the same conceptualization. However, the analytic solution has overestimated the interface location, for it ignores the mixing factor. As it is shown in Figure 6, the saline water (dark brown color) is overlaid by the mixing zone which in turn is overlaid by the land driven fresh groundwater discharge. However, this structure is missed on the analytic solution.

Case 2: This conceptualization was based on the Bakker [16] analytic solution for the interface problems. Similar to case- 1 above, the concentration contour line at the $50 \%$ of the maximum concentration was chosen to represent the interface location. Accordingly, the tip of the seawater-freshwater interface was found at an offshore distance of $300 \mathrm{~m}$; while, the toe was found at an inland distance of $700 \mathrm{~m}$ (Figures 7 and 8 ). Similar to case-1, the distance to the toe location found in this case is shorter than the distance found in case- 2 of the analytic solution section.

Comparison between case- 1 and case- 2 results of the numerical modeling: Similar to the analytic solution, the numerically simulated results for case- 1 and case- 2 are also different. Furthermore, the locations and shapes of the interfaces in these two cases are different. The main reason for this situation is, therefore, the SGD incorporated in case-2. Therefore, ignoring the influence of SGD on the interface position when modeling coastal groundwater systems, especially those with confined and semi-confined sections, overestimates the interface location.

Comparison between analytic and numerical modeling results: Analytic solutions for the position of the saltwater-freshwater interface are based on the sharp interface approximations. The advantages of analytic solutions are that they are considerably less computationally intensive and require less data [11]. However, sharp interface approximations can only be used in areas where the mixing zone can be ignored; while, in reality, mixing between freshwater and saltwater occurs in all coastal aquifers as a result of dispersion, changes in head, changes in hydraulic conductivity and tides [25]. In fact, the extent of mixing varies from a few tens of centimeters in tight clays or sandstone to several tens of meters in karstic limestone [26]. But mixing is always there, regardless of its extents. Therefore, analytic solutions obviously overestimate the extent of saltwater penetration further inland.

In reality, freshwater overlies the mixing zone which in turn overlies saline water. It is not, therefore, possible to provide stable and accurate results using analytical solutions, unless a correction factor is incorporated to include the influence of mixing. However, the complex density-dependent groundwater flow and solute transport models provide stable and convincing results when employed with proper spatial and temporal discretisations.

In this case, simulation results for the interface heads from the two analytic solutions were corrected by the empirically derived dispersion factor $\left[1-\left(\alpha_{T} / b\right)^{1 / 6}\right]$ developed by Pool and Carrera [12] to include the influence of mixing on the interface location, where $\alpha_{T}$ is transverse dispersivity and $b$ is aquifer thickness. While, simulation results for 


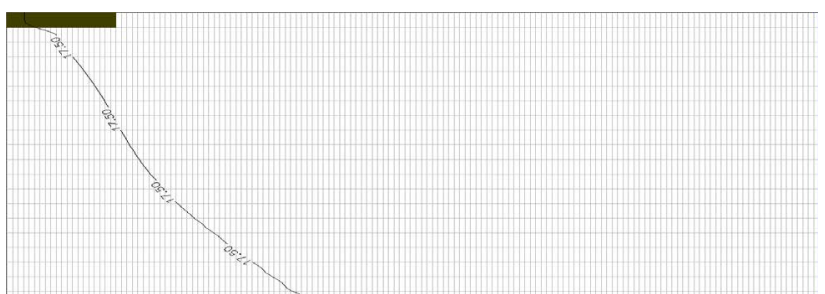

Figure 8: Seawater-freshwater interface location (at $50 \%$ of the maximum concentration) of case-2.

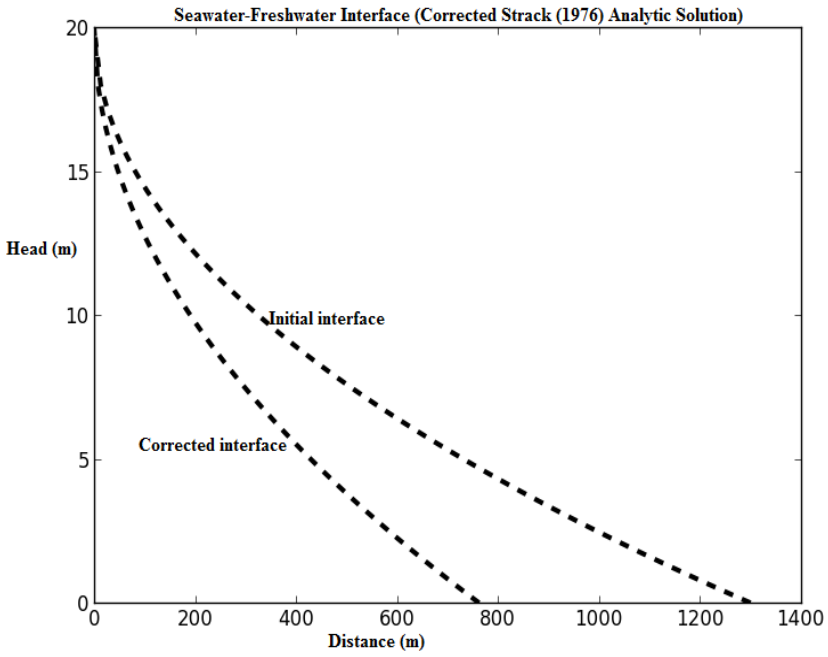

Figure 9: Corrected Strack (1976) Seawater-Freshwater interface.

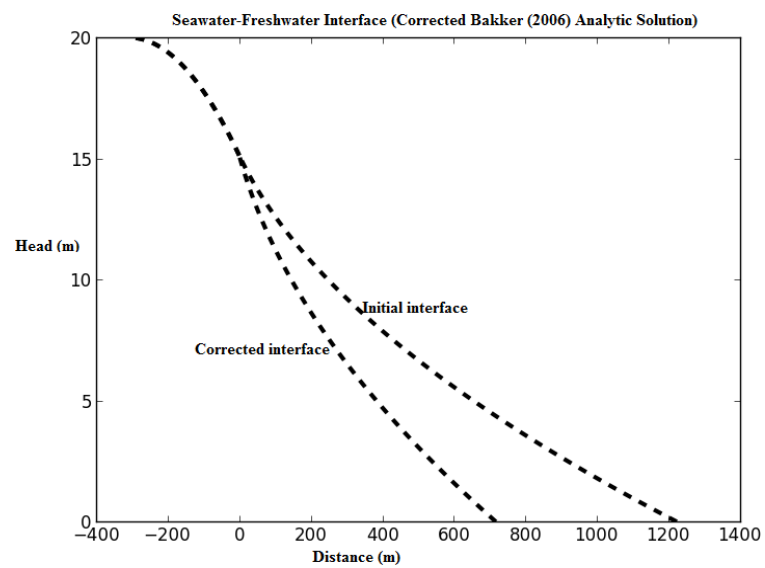

Figure 10: Corrected Bakker (2006) Seawater-Freshwater interface.

the saltwater-freshwater interface position from the density-dependent Solute Transport Numerical Model (SEAWAT), which includes advection and dispersion, are believed to be accurate.

The transverse dispersivity used in both of the two cases of the numerical modeling section was 0.1 . Therefore, the correction factor $(f)$ can be calculated $\stackrel{\text { dels follogws: }}{b})^{=}$

$$
f=\left[1-\left(\frac{0.1}{20}\right)^{1 / 6}\right]=0.5865
$$

As shown in Figures 9 and 10, the analytic solution results for both case- 1 and case- 2 were corrected by the correction factor $(f)$. Finally, the corrected analytic solutions became very close to the numerically simulated values. Initially, the location of the toe for case- 1 was found at an inland distance of $1300 \mathrm{~m}$; while, it was found at a distance of 880 $\mathrm{m}$ from the numerical modeling. However, after correcting the analytic solution result, the toe was found at an inland distance of $762.43 \mathrm{~m}$ (Figure 9), which is very close to the numerically simulated value than the initial one.

Similarly, the analytically calculated toe location for case- 2 was also corrected by the empirically derived dispersion factor (0.5865). Initially, the location of the toe for case-2, was found at an inland distance of $1222.97 \mathrm{~m}$; while, it was found at a distance of $700 \mathrm{~m}$ from the numerical modeling. However, after correcting the analytic solution result, the toe was found at an inland distance of $717.25 \mathrm{~m}$ (Figure 10), which is also very close to the numerically simulated value than the initial one.

\section{Conclusion}

In conclusion, two inferences can be derived from this work. Firstly, SGD has an impact on the seawater-freshwater interface position. Hence, model extents offshore should be taken into account whenmodeling groundwater flow in coastal aquifer systems to incorporate the influence of SGD on the interface position. In this case, simulation results based on the Strack [6] analytic solution for the interface problems have overestimated the interface location, compared to the results based on Bakker [16] analytic solution. The reason for this situation is that the Strack [6] solution neglects model extents offshore. Thus, it needs to be modified to incorporate the influence of SGD on the interface position.

Secondly, analytic solutions overestimate the location of the seawater-freshwater interface, for they are based on the sharp interface approximations. Therefore, results from analytic solutions need to be corrected by the empirically derived dispersion factor $(f)$ to include the mixing factor in the solution so as to compare results from numerical modelling with those from the analytical solutions.

\section{References}

1. Morgan LK, Werner AD, Morris MJ, Teubner MD (2013) Application of a rapid assessment method of SWI: Willunga Basin, South Australia. In: Wetzelhuetter C (ed.) Groundwater in the Coastal Zones of Asia - Pacific. Coastal Research Library. Springer: 205-225.

2. Post VEA, Groen J, Kooi H, Person M, Ge S, et al. (2013) Offshore freshwater reserves as a global phenomenon. Nature review: 504.

3. Moore WS (2009) Submarine Groundwater Discharge. University of South Carolina, Columbia, SC, USA.

4. Church TM (1996) An underground route for the water cycle. Nature 380: 579580

5. Beebe C, Ferguson G, Kennedy G (2011) Analytical modelling of saltwater intrusion: tests from Nova Scotia and the eastern United States, geohydro, Nova Scotia, Canada.

6. Strack ODL (1976) A single-potential solution for regional interface problems incoastal aquifers. Water Resour Res 12: 1165-1174.

7. Aharmouch A, Larabi A (2001) Numerical modeling of saltwater interface upconing in coastal aquifers, First international conference on saltwater intrusion and coastal aquifers-monitoring, modeling, and management, 
Citation: Shishaye HA (2016) Groundwater Flow Modeling in Coastal Aquifers: The Influence of Submarine Groundwater Discharge on the Position of the Saltwater-Freshwater Interface. J Coast Zone Manag 19: 419. doi:10.4172/2473-3350.1000419

\section{Essaouira, Morocco.}

8. Wriedt G, Bouraoui $F(2009)$ Large scale screening of seawater intrusion risk in Europe, Methodological development and pilot application along the Spanish Mediterranean coast, European Commission, Joint Research Centre, Institute for Environment and Sustainability.

9. Mazi A (2014) Seawater intrusion risks and controls for safe use of coastal groundwater under multiple change pressures, Doctoral thesis, Department of Physical Geography and Quaternary Geology, Stockholm University, Sweden.

10. Naderi M, Kermani M, Barani G (2013) Possibility of groundwater operation in coastal aquifers for prevention of seawater intrusion. BEPLS 2: 11.

11. Werner AD, Ward JD, Morgan LK, Simmons CT, Robinson NI, Teubner MD (2012) Vulnerability indicators of seawater intrusion. Ground Water 50: 48-58.

12. Pool M, Carrera J (2011) A correction factor to account for mixing in GhybenHerzberg and critical pumping rate approximations of seawater intrusion in coastal aquifers. Water Resour Res: 47.

13. Huyakorn PS, Wu YS, Park NS (1996) Multiphase approach to the numerical solution of a sharp interface saltwater intrusion problem. Water Resour Res 32: 93-102.

14. Motz LH (1992) Saltwater upconing in an aquifer overlain by a leaky confining bed. J Ground water 30: 192-198.

15. Bower JW, Motz LH, Durden DW (1999) Analytical solution for determining the critical condition of saltwater upconing in a leaky artesian aquifer. J Hydrol 221 43-54.

16. Bakker M (2006) Analytic solutions for interface flow in combined confined andsemi-confined. Coastal aquifers. Elsevier Adv Water Resour 29: 417-425.

17. Werner AD, Bakker M, Post VEA, Vandenbohede A, Lu C, et al. (2013) Seawater intrusion processes, investigation and management: Recent advances and future challenges. Elsevier Advances in Water Resources 51: 3-26.

18. Sherif M, Singh V (1999) Effect of climate change on seawater intrusion in coastal aquifers. Hydrol Process 13: 1277-1287.

19. Johannes RE (1980) The ecological significance of the submarine discharge of groundwater. Mar Ecol Prog Ser 3: 365-373

20. Fanning KA, Byrne RH, Breland JA, Betzer PR, Moore WS, et al. (1981) Geothermal springs of the west Florida continental shelf, Evidence for dolomitization and radionuclide enrichment. Earth Planet SciLett, 52: 345-354.

21. Moore WS (1996) Large groundwater inputs to coastal waters revealed by 226Ra enrichments. Nature 380: 612-614.

22. Li L, Barry DA, Stagnitti F, Parlange JU (1999) Submarine groundwater discharge and associated chemical input into a coastal sea. Water Resour Res 35: 3253-3259.

23. Burnett WC, Aggarwal PK, Aureli A, Bokuniewicz H, Cable JE, et al. (2006) Quantifying submarine groundwater dischargein the coastal zone via multiple methods. Science of the Total Environment 367: 498-543.

24. Kooi H, Groen J (2001) Offshore continuation of coastal groundwater systems; predictions using sharp-interface approximations and variable-density flow modeling. J Hydrol 246: 19-35.

25. Shalev E, Lazar A, Wollman S, Kington S, Yechieli Y, et al. (2008) Biased monitoring of fresh water-saltwater mixing zone in coastal aquifers. Ground Water 47: 49-56

26. Dausman A, Langevin CD (2005) Movement of the saltwater interface in the surficial aquifer system in response to hydrologic stresses and watermanagement practices, Broward County, Florida, U.S. Geological Survey, Scientific Report: 1-69. 